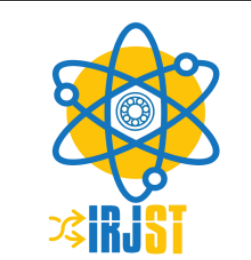

Available online at https://www.irjst.com/

International Research Journal of Science and Technology

ISSN:2707-3955

DOI: https://doi.org/10.46378/irjst.2019.010105

\title{
An Analysis of Quality Characteristics of Bamboo/Cotton Blended Yarns of Rotor and Ring Spun
}

\author{
G. Nagarajan ${ }^{1 *}$, Dr. T. Ramachandran ${ }^{2}$ and S.Boobalan ${ }^{3}$ \\ ${ }^{1}$ Research Scholar, Karpagam University, Coimbatore, Tamilnadu, India. \\ ${ }^{2}$ Principal,Karpagam Institute of Technology, Coimbatore, Tamilnadu, India. \\ ${ }^{3}$ B.Tech Textile Technology, Karpagam University Coimbatore, Tamilnadu, India.
}

\section{Published : 2019}

\begin{abstract}
Denim fabrics are in general manufactured by using $100 \%$ cotton fibers. A novel attempt has been made by using bamboo/cotton yarns in warp and weft directions to produce denim fabrics using ring yarns in warp and rotor yarns in weft directions. In this research work, bamboo/cotton yarns are manufactured in different blend compositions like 100\% bamboo, 100\% cotton,70:30, 50:50 and $30: 70$ ratios. Ne 10 and $\mathrm{Ne} 16$ carded yarns are manufactured from both the ring and rotor spinning systems. The yarns manufactured out of these two spinning systems have been critically analyzed for their quality characteristics like Unevenness, Imperfections, Hairiness, friction, abrasion, strength and elongation. The influence of blend ratios on yarn quality characteristics in ring and rotor yarns has been analyzed and the optimum blend proportion which gives the best quality has been investigated.
\end{abstract}

Key Words

Denim

Bamboo

Ring

Roto

Friction

Abrasion

Copyright@2019:G. Nagarajan., Dr. T. Ramachandran., S.Boobalan.This is an open access distribution, and reproduction in any medium, provided Access article distributed under the Creative Commons Attribution License the original work is properly cited License, which permits unrestricted use.

Citation:G. Nagarajan., Dr. T. Ramachandran., S.Boobalan. "An analysis of Quality characteristics of Bamboo/cotton blended yarns of Rotor and Ring spun ”, International Research Journal of Science and Technology, 1(1), 31-34 , 2019

\section{Introduction}

Denim is of the most prominent category in India's garment sector. The denim market in India is skewed towards men's segments with 80 percent contribution coming from it. Women's denim sector contributes 12 percent to the market and the children's wear contribute the rest 8 percent. Furthermore, only 100\% cotton of coarser counts are used for the manufacture of denim fabrics. Bamboo fabric has a natural sheen and softness that feels and drapes like silk but is less expensive and more durable.

\footnotetext{
${ }^{*}$ Corresponding author :G. Nagarajan

Research Scholar, Karpagam University,

Coimbatore,Tamilnadu, India

Email: ganapathy.nagarajan2013@gmail.com
}

Bamboo clothing is easy to launder in a clothes washer and dryer. Because of the smooth and round structure of its fibers, bamboo clothing is soft and non-irritating, even to sensitive skin because of the smooth and round structure of its fibers. In this research work, bamboo fibers and its blends with cotton has been tried to produce the denim fabrics. In this research work denim fabric made out of $100 \%$ bamboo yarns, $100 \%$ cotton in both the ring spun and rotor spun and its blends with cotton of different blend ratios like 70:30, 50:50 and 30:70. The objectives of the work is to study the antimicrobial properties, wear ability studies and offer suitable recommendations with special reference to the blend composition and finishing treatments. 


\section{Materials and Methods}

$\mathrm{Ne} 10$ and Ne 16 carded yarns of $100 \%$ cotton and blends of bamboo/cotton spunin rotor spinning system in the modern machineries for the production of denim fabrics. The rotor yarns are manufactured with a rotor diameter of $40 \mathrm{~mm}$, rotor speed of 70,000 rpm and the opening roller speed of $8000 \mathrm{rpm}$. . The yarns produced were tested for their physical properties in the testing laboratory. The yarn samples were conditioned in the testing atmosphere of $65 \% \mathrm{RH}$ and $25^{\circ} \mathrm{C}$ to get reliability in the results. The fibre properties of the cotton and bamboo fibers are shown in the Table 1. (ASTM D 3822/D $3822 \mathrm{M}$ - 14).

Table1. Fibre properties of Cotton and Bamboo fibers

\begin{tabular}{lll}
\hline Fibre properties & Cotton & Bamboo \\
\hline Fiber length $(\mathrm{mm})$ & 26 to 31 & 40 \\
\hline Fibre strength $(\mathrm{g} / \mathrm{tex})$ & 22 & 27 \\
\hline Fibre denier & 1.5 & 1.27 \\
\hline Fiber elongation $(\%)$ & 6 & 18.35 \\
\hline
\end{tabular}

Table 2.Fibre blend ratios of Bamboo and Cotton yarns

\begin{tabular}{llll}
\hline Fibres & Blend Ratio & Count spun & $\begin{array}{l}\text { Spinning } \\
\text { system }\end{array}$ \\
\hline Bamboo & $100 \%$ & $\mathrm{Ne} \mathrm{10} \mathrm{\&}$ & Ring and \\
& & $\mathrm{Ne} \mathrm{16}$ & Rotor \\
\hline Cotton & $100 \%$ & $\mathrm{Ne} \mathrm{10} \mathrm{\&}$ & Ring and \\
& & $\mathrm{Ne} \mathrm{16}$ & Rotor \\
\hline Bamboo/ & $70 \%: 30 \%$ & $\mathrm{Ne} \mathrm{10} \mathrm{\&}$ & Ring and \\
Cotton & & $\mathrm{Ne} \mathrm{16}$ & Rotor \\
\hline Bamboo/ & $50 \%: 50 \%$ & $\mathrm{Ne} \mathrm{10} \mathrm{\&}$ & Ring and \\
Cotton & & $\mathrm{Ne} \mathrm{16}$ & Rotor \\
\hline $\begin{array}{l}\text { Bamboo/ } \\
\text { Cotton }\end{array}$ & $30 \%: 70 \%$ & $\mathrm{Ne} \mathrm{10} \mathrm{\&}$ & Ring and \\
\hline
\end{tabular}

\section{Results and Discussions}

The mechanical processing of the $100 \%$ cotton, bamboo/cotton blends manufactured to produce carded yarns in rotor spinning systems have been studied The physical properties of the yarns in terms of Unevenness percentage (U\%), imperfections like thin places, thick places, neps and other quality attributes like hairiness values, friction and abrasion characteristics of the yarns have been dealt in the following sections.

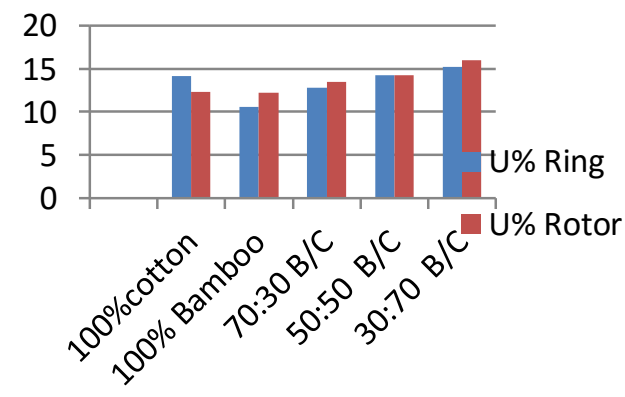

Graph 1. Yarn unevenness(U\%) and for Ne 10 ring and rotor spun yarns.

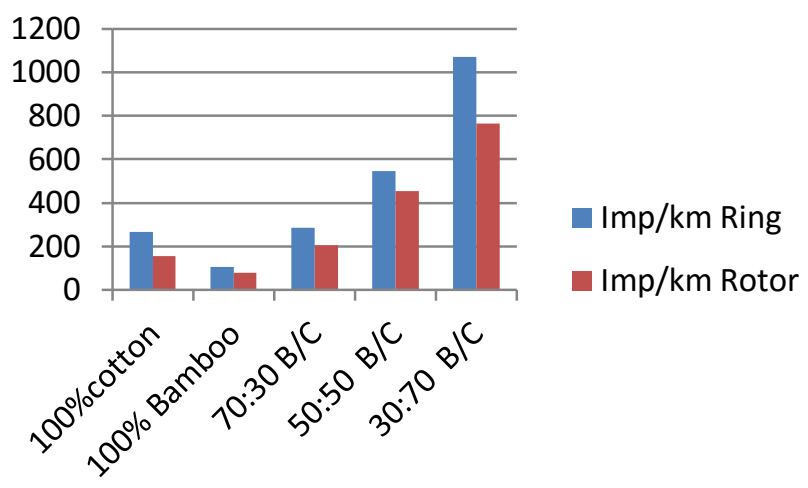

Graph 2.Imperfections $/ \mathrm{km}$ of $\mathrm{Ne} 10$ for Ring and Rotor spun yarns.

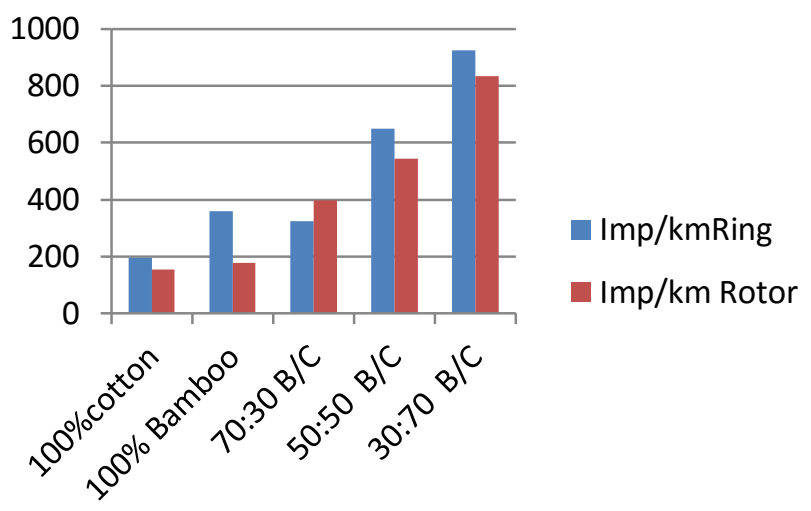

Graph 3. Unevenness (U\%) of Ne 16 for Ring and Rotor spun yarns

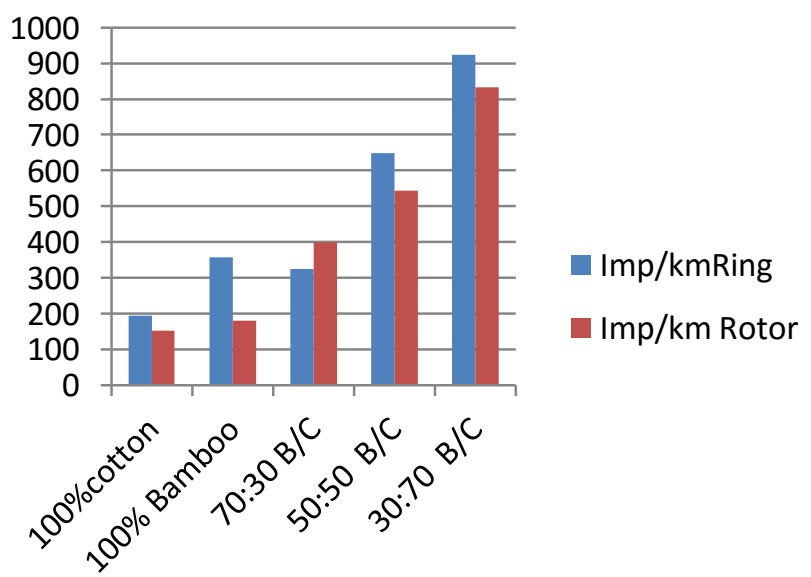

Graph 4. Imperfections $/ \mathrm{km}$ of counts Ne 16 ring and rotor spun yarns

From the Graph 1,2,3\&4. For the counts $\mathrm{Ne} 10$ and $\mathrm{Ne}$ 16 rotor spun yarns, the unevenness (U\%) level and the imperfection values that is mass variation per unit length is lower in $100 \%$ bamboo yarns and in the blend of 70:30 bamboo/cotton blended yarns. for rotor spun yarns. This is attributed to the better uniformity in 
fiber length and no short fibers in bamboo fibers. In the other blends except 70:30 B/C, other blends show higher unevenness values. It means the increase in proportion of the natural fiber cotton which is influenced by higher proportion of short fibers and variation in fiber length uniformity. This is also reflected in the imperfection values in the yarns.

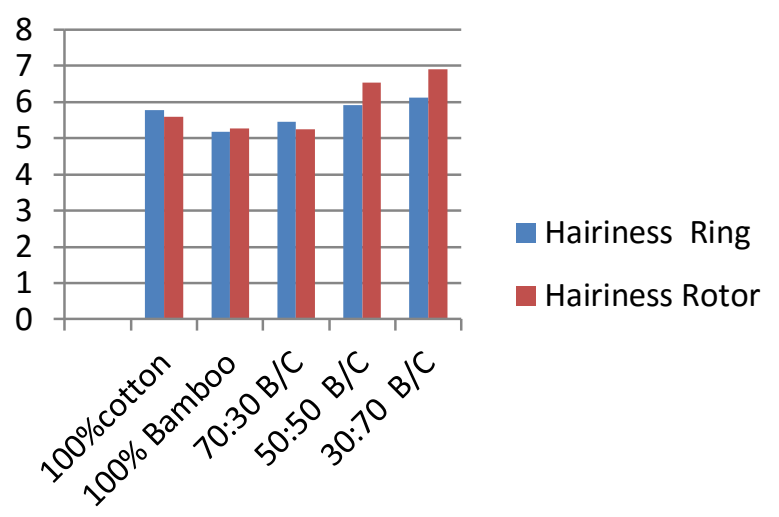

Graph 5.Hairiness values of the Ne $10100 \%$ for ring and rotor

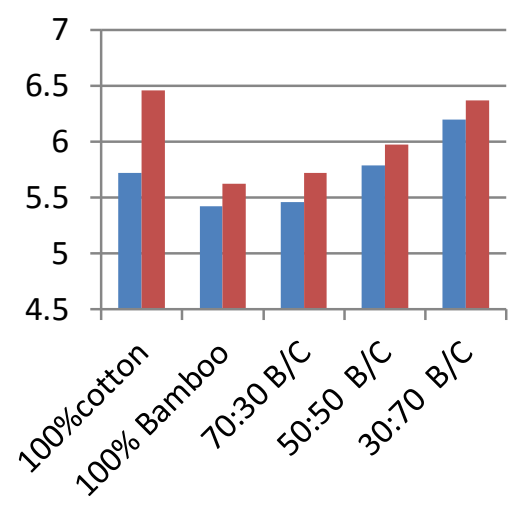

Hairiness Ring

Hairiness Rotor

Graph 6.Hairiness Index for Ne 16 ring and rotor spun yarns.

From the Graph 5\& Graph 6, Hairiness is defined as the number of protruding fibers from the body of the yarn after the yarn structure is formed. It affects many properties like fabric appearance, running performance in weaving and knitting. Lower the hairiness value better will be the yarn quality and fewer problems will be encountered in the downstream processes. It is observed that the hairiness values of $100 \%$ bamboo yarns of $\mathrm{Ne} 10$ and $\mathrm{Ne} 16$ exhibit lower hairiness values than $100 \%$ cotton and also with the various blend ratios. It is attributed to the absence of short fibers better yarn irregularity and uniformity in the bamboo fibers and also better binding of fibers in to the yarn structure which is responsible for the lower hairiness values.
Yarn friction test results of the rotor spun yarns are tested in Lawson-Hemphill tester and the results are shown in the Graph 7.

Yarn abrasion is defined as the ability of the yarn to withstand the abrasive action in the subsequent processes like weaving, knitting. It is evaluated by subjecting the yarn to abrasive cycles and the number of strokes required to break the yarn samples. Higher the abrasive values, higher will be the abrasion resistance of the yarns.

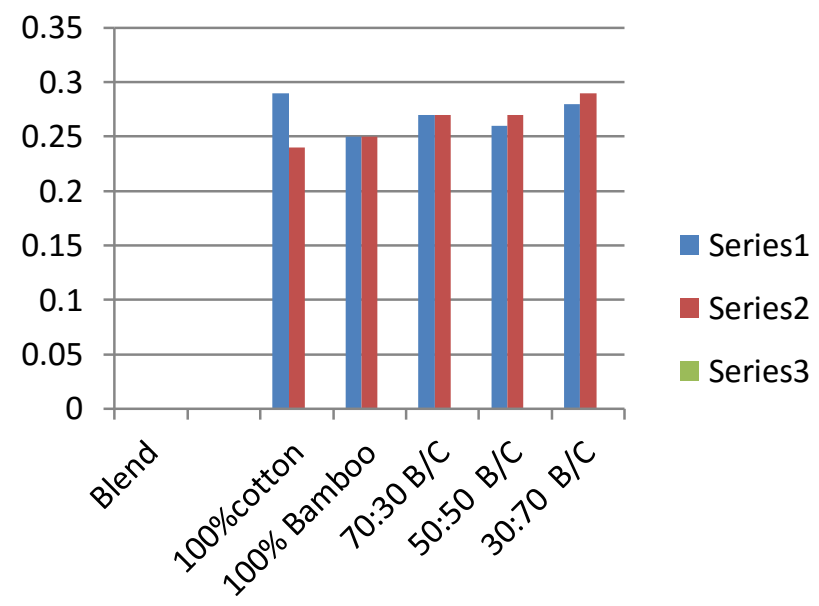

Graph 7. Yarn friction values for Ne 10 ring and rotor spun yarns.

The yarn friction values for the count $\mathrm{Ne} 10$ for ring and rotor yarns show that there is only marginal difference in the friction values for bamboo and its blends. It is due to the presence of surface irregularities on the cotton fibers and unwaxed.

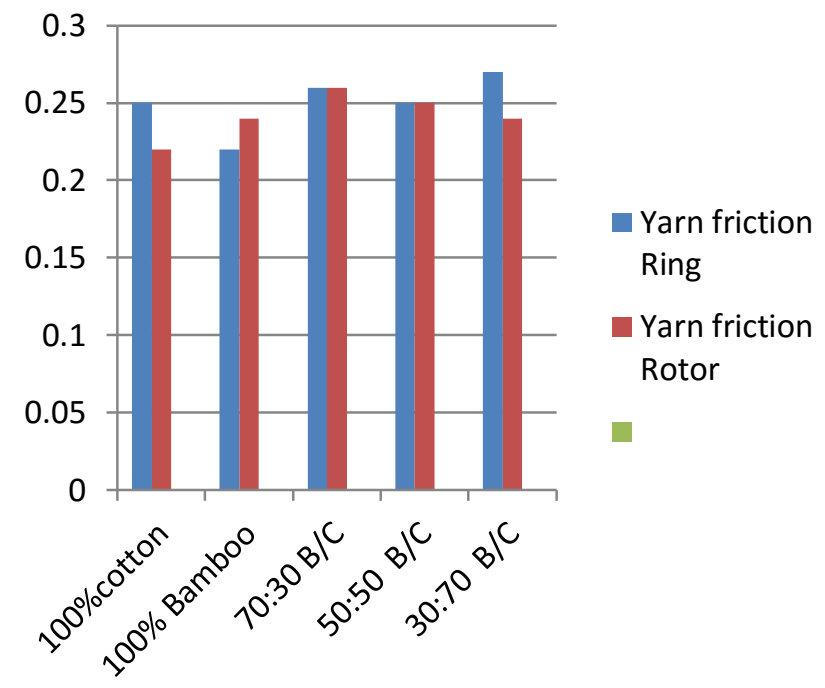

Graph 8. Yarn friction results for Ne 16 ring and rotor spun yarns. 
Yarn abrasion test results of cotton and bamboo/cotton blends are shown in the Graph 9.

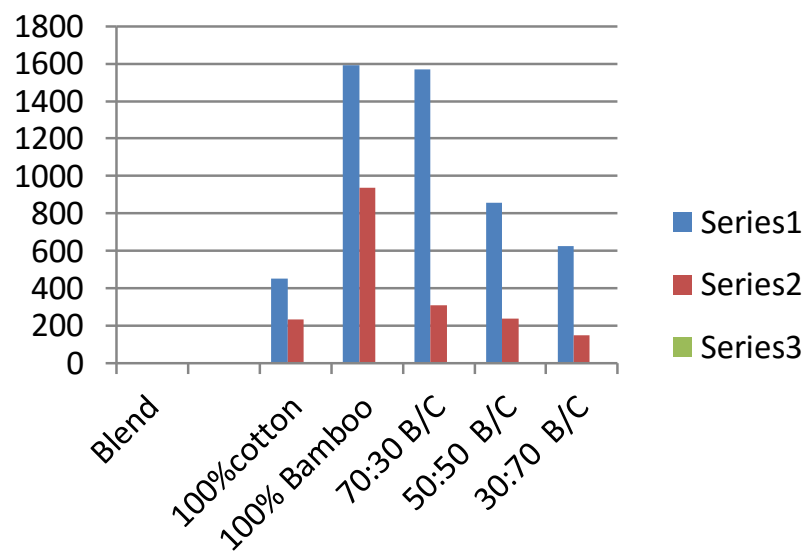

Graph 9. Yarn abrasion test results for Ne 10 ring and rotor spun yarns.

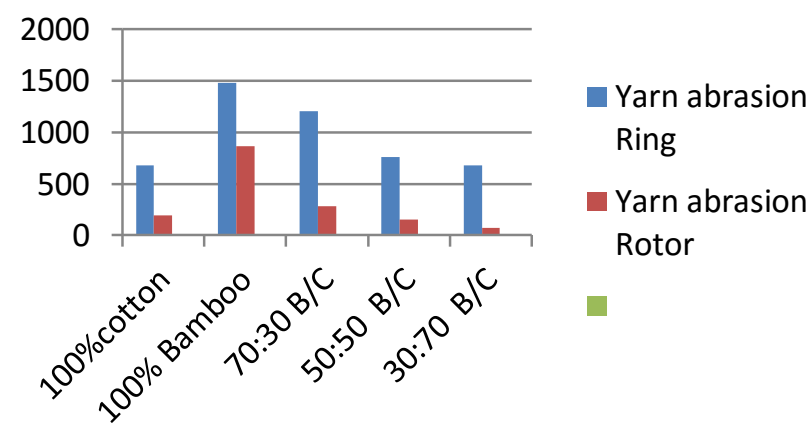

Graph 10.Yarn abrasion values for Ne 16 ring and rotor spun yarns.

From the Graph $9 \& 10$, the abrasion resistance of $100 \%$ bamboo fibers shows higher abrasion resistance than its counterparts. It is due to the regenerated fibres which has higher strength and elongation and capable of resisting the abrasive cycles even at higher speeds than the $100 \%$ cotton fibers.

\section{Conclusions}

The influence of the bamboo fibers in the blends have a greater impact on yarn characteristics for the two counts of Ne10 and $\mathrm{Ne} 16$ spun on rotor spinning systems. Yarns spun out of $100 \%$ bamboo fibers and 70:30 blends in rotor spinning systemshow better unevenness and imperfection values by $38 \%$ and $34 \%$ than the ring spinning system. In rotor spinning, due to the back doublings in the rotor and less process stages, the imperfections are lower as compared to ring spinning system which has more process stages and influence of drafting irregularities in every stage. This trend is observed in $\mathrm{Ne} 16$ count also. Hairiness values are better in ring spun yarns of $100 \%$ bamboo fiber and in blend ratio of 70:30 which is due to the better binding of fibers in the spinning process and with higher fiber length uniformity. The difference in hairiness values spun on ring and rotor system is in the range of 2 to $4 \%$. There is no significant difference in the yarn friction values of all the materials like cotton and bamboo blends which shows the surface irregularities in both the fibers. Good abrasion resistance values of $100 \%$ bamboo fibers and in the blend of 70:30 bamboo/cotton blends of $43 \%$ and $34 \%$ in ring spun yarns than the rotor spun yarns in both the counts. This is due to the better binding of fibers in to the yarn core and higher yarn strength due to the helical twisting of all the fibers in to the yarn core .

\section{References}

1. Subrata Das \& V.K. Kothari. Moisture vapour transmission of cotton fabrics . Indian Journal of Fibre and Textile Research. 2007;37; $151-156$.

2. Slater. K. Progress in Textile Science and Technology Testing and Quality management; 1999; $360-385$.

3. Sudipta S. Mahish, A.K. Patra\&Rashmi Thakur. Functional properties of bamboo/polyester blended knitted apparel fabrics . Indian Journal of Fibre and Textile Research 2012; 37; $231-237$.

4. WiahWardiningsih\& Olga Troynikoy Influence of cover factor on liquid moisture transport performance of bamboo knitted fabrics. Journal of Textile Institute 2012;103; 89 - 98.

5. G.K.Tyagi, S. Bhattacharya \& G. Kheredekar Comfort behaviour of woven bamboo-cotton ring and MJS yarn fabrics . Indian Journal of Fibre and Textile Research 2011;36; 47 - 52. 